\title{
Study on vehicle running-in method based on oil element monitoring
}

\author{
Heping Wang, Xuegong Liu \\ Beijing Institute of Special Vehicles, Beijing, 100072 \\ Email:whpzhjh@sina.com
}

Keyword: Running-in, Oil spectrum Monitoring, dis-assembly method,wear

Abstract:In order to improve the contact state of the friction surfaces of various parts, reduce friction and wear, improve the mechanical efficiency of power transmission system, and the reliability life of the vehicle,the reliable running-in must be carried out in a short time.In this paper,different running-in schemes are designed,oil liquid spectrum monitoring, an dis-assembly method are used to analyze the running-in process and results, a reasonable running- in is obtained,the running-in time is shorten, and cost is saved.

\section{Introduction}

In the use of heavy vehicles, first, it need to be running-in to improve the mechanical efficiency of the power and transmission system, and to extend the reliability life of the power and transmission system. A good running -in method should be a short running -in time, small wear quantity, high wear resistance. In order to improve the running -in performance, a reasonable running -in standard should be chose, reasonable rules should be gradually increase the load and friction speed, so that the surface quality is improved, the final stage of running -in period t of the work conditions should be closed to the use of conditions.

With the development of science and technology, more and more technical methods are applied to the research of running- in. The methods includes oil analysis method, surface roughness analysis, SEM analysis, friction power analysis, and dis-assembly analysis. Above research methods has its own advantages and disadvantages, such as topography method, compression pressure, remove microscopic examination etc just reflect the results and do not reflect the process, and the oil spectrum analysis method and iron spectrum analysis method can analyze the running -in process, and have the advantages of simple operation, low cost, high efficiency. Atomic emission spectral analysis can determine the mass fraction of the elements in the oil, and it has important significance for research of the quality of wear and wear parts. Dis-assembly analysis method is a direct method to check the transmission system parts after running-in.In this paper,the oil atomic emission spectral analysis method and dis-assembly method are used to analyze the running-in process and results

\section{Vehicle integrated transmission characteristics}

The vehicle integrated transmission device is based on the principle of stream transmission,the system are made of hydrodynamic torque converter, lockup clutch, hydraulic clutch, shift gears, hydraulic manipulation shift valve, collecting planetary and a plurality of constant pressure valve comprises a prequel.

The running-in of integrated transmission device is a series of mechanical, physical and chemical phenomena of the synthesis and extremely complex surface damaged process. In the running-in process, there are many friction pairs to participate, and the friction pair of material 
composition is complex. In the actual test, the road is complex and varied,.In the actual operation process, the integrated transmission device generally has 6 to 4 forward gears, different gears correspond to different friction pairs.But the sliding friction pair running time is long.Each file in the running-in process contains a variety types of friction pairs, there are rolling and sliding.The running-in time of different friction pairs are not same.Rolling friction pair running-in need short time to achieve the purpose.According to the characteristics of the vehicle integrated power transmission device, the running-in plan should considered the uniform collocation of the different friction of the file to ensure that each friction pair get effective running-in in short time.

According to the wear law, by detecting the variation of wear rate and wear, the evaluation of the running period of the integrated transmission can be evaluated. The wear particles are evenly distributed in the oil liquid of their internal circulation in the running-in process, by detecting the amount of wear particles and morphology information, the quality of running-in can be judged.

Table .1 elements sources in vehicle transmission oil

\begin{tabular}{|c|c|c|c|c|c|}
\hline element & $\mathrm{Fe}$ & $\mathrm{Gr}$ & $\mathrm{Cu}$ & $\mathrm{AL}$ & $\mathrm{Si}$ \\
\hline source & gear, shaft, & gear, shaft, \\
& $\begin{array}{c}\text { rolling bear, } \\
\text { box }\end{array}$ & $\begin{array}{c}\text { tolling bear, } \\
\text { box }\end{array}$ & $\begin{array}{c}\text { turbine, rolling } \\
\text { bearing }\end{array}$ & $\begin{array}{c}\text { box,sand, } \\
\text { rolling bear }\end{array}$ & sand \\
& box & & & \\
\hline
\end{tabular}

\section{Running -in scheme research}

The heavy vehicles often are driven on undulating dirt road gravel road and paved road,the dirt road and gravel road conditions are relatively harsh, the working conditions of power and transmission system are complex and changeable.According to the running-in optimization target,in the design running-in scheme,the operating conditions of the vehicle should be close to the actual work situation and the various friction parts should be made full friction.

Three heavy vehicles are chose in the running-in test, the vehicle power system, weight and external size are the same, Vehicles are driven around 10000 kilometers in the test, the traveling road includes undulating dirt road, gravel and concrete road pavement..In previous experiments, the vehicle running-in mileage on undulating dirt road is set 500 kilometers

Due to the large fluctuation of the undulating dirt road, , in the driving process, the gears are often changed, and the vehicle speed is lower, the vehicle is running at the speed of $20 \sim 30 \mathrm{~km} / \mathrm{h}$, Running- in scheme is shown in table 2.

Table. 2 running-in scheme on dirt road

\begin{tabular}{|c|c|c|c|}
\hline file & first file & second file & third file \\
\hline velocity $(\mathrm{km} / \mathrm{h})$ & 15 & 20 & 30 \\
\hline Engine speed(r/min) & 800 & 1000 & 1200 \\
\hline time(min) & 40 & 40 & 40 \\
\hline $\begin{array}{c}\text { Sampling } \\
\text { interval }(\text { min })\end{array}$ & \multicolumn{4}{|l}{} \\
\hline
\end{tabular}

The hardness of sand gravel road is larger, and there is a certain degree of fluctuation, so the running speed of the vehicle is at $20 \sim 35 \mathrm{~km} / \mathrm{h}$. 
Table. 3 running-in scheme on sand gravel road

\begin{tabular}{|c|c|c|c|}
\hline file & first file & second file & third file \\
\hline velocity $(\mathrm{km} / \mathrm{h})$ & 20 & 25 & 35 \\
\hline Engine speed(r/min) & 1000 & 1100 & 1200 \\
\hline time(min) & 40 & 40 & 40 \\
\hline $\begin{array}{c}\text { Sampling } \\
\text { interval(min) }\end{array}$ & & \multicolumn{2}{|c}{20} \\
\hline
\end{tabular}

On the paved road, vehicle gear and speed is easy to change, according to the actual situation of the vehicle, on paved road vehicles run at speeds of $20 \sim 50 \mathrm{~km} / \mathrm{h}$.

Table.4 running-in scheme on paved road

\begin{tabular}{|c|c|c|c|c|}
\hline file & $\begin{array}{c}\text { second } \\
\text { file }\end{array}$ & third file & fourth file & fifth file \\
\hline velocity $(\mathrm{km} / \mathrm{h})$ & 20 & 30 & 40 & 50 \\
\hline Engine speed(r/min) & 1000 & 1200 & 1600 & 2000 \\
\hline time(min) & 40 & 40 & 40 & 40 \\
\hline $\begin{array}{c}\text { Sampling } \\
\text { interval(min) }\end{array}$ & \multicolumn{4}{|c}{} \\
\hline
\end{tabular}

The test scheme is carried out for 2 to 3 cycles until the friction of the transmission system is stable, and stable running-in layer are formation are taken shape.

\section{Test data analysis}

\section{Oil spectral analysis}

The contents of $\mathrm{Fe}, \mathrm{Cu}, \mathrm{Cr}$ and other elements in the lubricating oil are analyzed by atomic emission spectrometry. The results are shown in Figure 1.

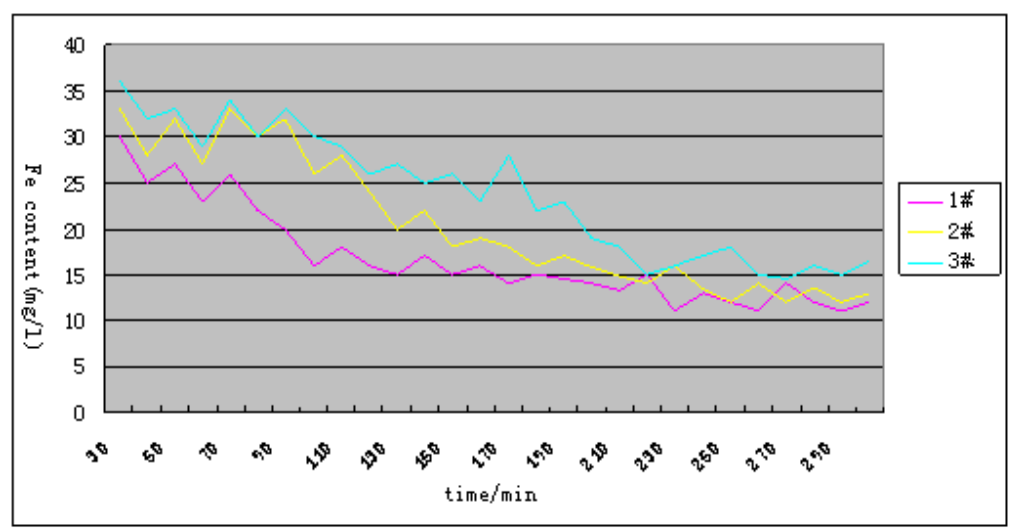

Figure. 1 variation of Fe element content in the running-in stage

The results show that the content of iron element in the No.2 and 3 vehicle at the beginning is higher than the 1 vehicle,because in the first 40 minutes of the running -in No.2 vehicle engine speed is higher than 1 vehicle.After running-in 40 minutes , the content of the iron element in the lubricating oil is increased by the increase of load and speed.

After 140 minutes, the No. 1 and 2 vehicle have completed a cycle,the concentration of iron is stable. While the number of No.3 vehicle due to the increase of load and speed, the content of iron is in the rising phase of volatility.

The content of iron after three running -in circulation is in a relatively stable trend, since the 
load and speed of the No. 3 vehicle is more than No. 1 and 2vehicle, so the content of iron element is higher than No.1 and 2 vehicle.

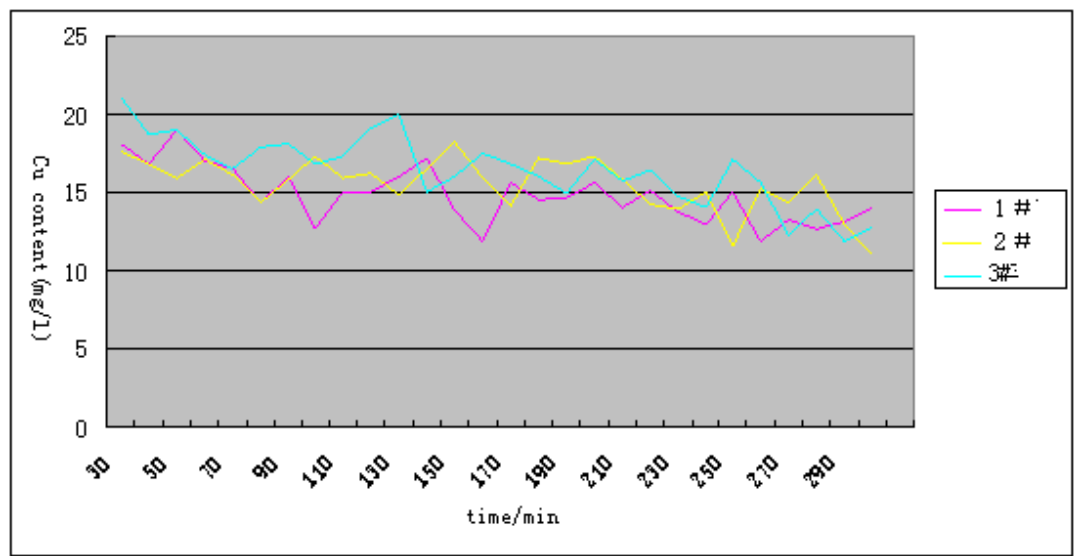

Figure. 2 variation of $\mathrm{Cu}$ element content in the running-in stage

From the figure, the concentration of $\mathrm{Cu}$ in the process of running-in process is relatively stable, the $\mathrm{Cu}$ is mainly due to the shift of the clutch friction plate, due to the same shift frequency in the test process, the difference is not big.Based on spectrum analysis, The contents of elements in the No.1, 2 and 3 schemes changes along with the running-in time roughly consistent,three running-in schemes are carried out effectively

The content of iron in the three vehicle lubricating oil begin to decrease with the running-in time, between 40 minutes and 80 minutes, the content of iron element increase to a certain degree, and then decrease. About 120 minutes, The No.1 and 2 go into next running-in cycle,then engine speed and load will not increase,the content of iron in the lubricating oil begins to be stable,the degree of running-in will not increases.But in No.3 scheme engine speed and speed continues to increase,the degree of running also continue to increase.

\section{Dis-assembly analysis}

The Transmission system of the three vehicles after the running- in experiment are dismantled.The part of the system is analyzed. ,however, the surface of the No. 1and 2 vehicle have not formed good appearance, and have not achieved the good results of running-in.The surface.No.3 vehicle parts is relatively good, basically has achieved the purpose of running-in.

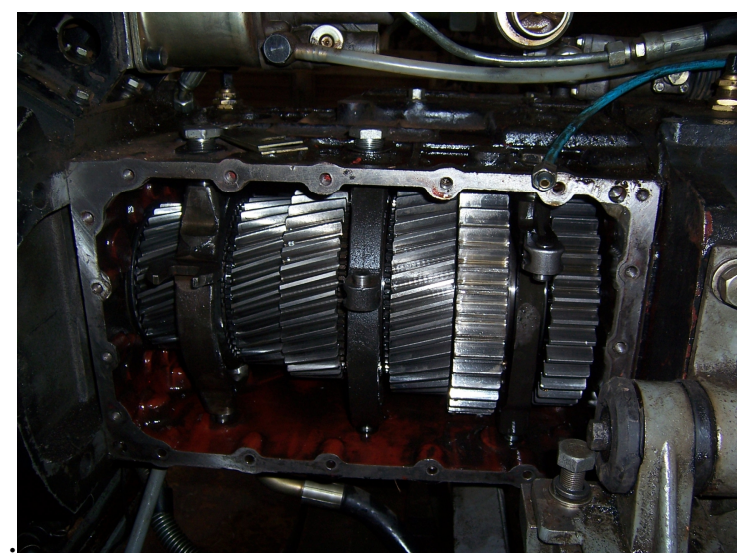

Fig. 3 internal gear wear of transmission system

\section{Conclusion}

Comparison three schemes, although In the No. 1 and 2 schemes the vehicle achieves a certain 
running-in, but due to the low speed and load,after a certain period of running-in time, the wear rate is slowed down, if the running-in is continued,the purpose of running-in will not achieve, it need to increase the speed and load.In No.3 scheme, the speed and load are higher than in No.1and 2,the high-speed stage of engine are also carried out, the running-in degree is more intense.in order to optimize the running-in process and in the shortest time to get the best running-in surface, the No.3 running- in should be used.From the dis-assembly results, the friction pairs of the No.3 vehicles have basically achieved the purpose of running-in,forming a relatively stable wear layer.

According to the elements content change in the vehicle oil, after the vehicles are driven about $350 \mathrm{~km}$, the elements content change tends to be stable, the basic purpose of running-in reaches, it is better than the $500 \mathrm{~km}$ running-in scheme .

\section{Reference:}

[1] FalconerKJ. FractalGeometry, MathematicalFoundationsand Ap-plications [M]. New York: John Wiley and Sons. 1990;

[2] Zhang Daolin, Yin Fengfu, Jing Yuanchang, a new quantitative analysis of wear paricles, tribology journal[J], 1999.2(2):110-113;

[3] Lang need, Zhou Yabin, Cheng type. The use of performance evaluation of a new formulation of system transmission in vehicle gear box, lubrication and seal[J], 2011, 36 (2): 114-117;

[4] Feng Fuzhou, Zheng Guojie, Xu Guichun. Study on hydraulic power device of a certain type of tank of oil monitoring, mechanical science and technology[J], 2007, 26 (3): 378-381;

[5] Ma Zhifeng, Li Xiaofeng. The diesel engine wear trend prediction, lubrication and sea[J]l, 2000, (1): 54-56. 